\title{
Chest Tube Ascariasis An Extremely Rare And Bizarre Presentation Of Colopleural Fistula With Traumatic Diaphragmatic Hernia : A Case Report And Review Of Literature
}

\author{
S Verma, V Sardana
}

\section{Citation}

S Verma, V Sardana. Chest Tube Ascariasis An Extremely Rare And Bizarre Presentation Of Colopleural Fistula With Traumatic Diaphragmatic Hernia : A Case Report And Review Of Literature. The Internet Journal of Parasitic Diseases. 2008 Volume 4 Number 1.

\begin{abstract}
A highly unusual and interesting case of Ascaris worms emerging through an intercostalchest tube is reported here because of its association with presence of colo-pleural fistula associated with left post traumatic diaphragmatic hernia detected subsequently. Review of the literature revealed only one reported case of chest tube ascariasis not associated with colopleural fistula ${ }^{1}$ and only five reported cases ${ }^{6-11}$ of colopleural fistula associated with diaphragmatic herniation, but none associated with pleural ascariasis. The combination of chest tube (pleural) ascariasis, colopleural fistula and left traumatic diaphragmatic hernia makes this case an extremely rare and bizarre presentation, probably only reported case of its kind and truly worthy for publication.
\end{abstract}

\section{CASE REPORT}

A 24-year-old woman, was admitted in the Emergency Department, complaining of left-sided chest pain and dry cough on and off for six months. Two day prior to admission, she had developed sudden-onset, sharp and progressively increasing in severity left-sided chest pain radiating to the back, aggravated by breathing, with no relieving factors. This pain was associated with dry cough and difficult breathing.

Her blood investigations revealed moderate anemia (hemoglobin $7.5 \mathrm{gm} / \mathrm{dl}$ ), mild leucocytosis with eosinophilia ( Total WBC count 14000/mm3, Absolute eosinophilic count $650 / \mathrm{mm} 3$ ). Her chest X-ray revealed moderate left pleural effusion.

Based on clinical and X-ray findings a chest tube was inserted, which drained a feculent odor dirty fluid. Around $24 \mathrm{hrs}$ subsequent to chest tube insertion two adult ascaris worm were noted emerging from the chest tube and collecting in the drainage bag. (Fig 1)

\section{Figure 1}

( Legend Fig 1. showing chest tube ascariasis with faecothorax within drainage bag)

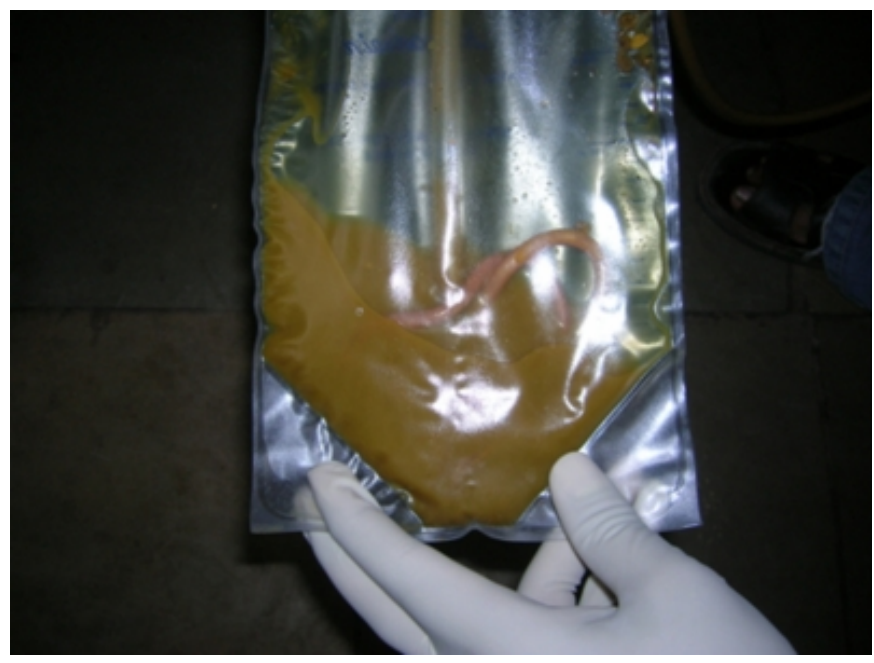

The patient was referred to radiology department for further investigation in view of this finding. Barium meal and follow through examination was carried out which revealed presence of left diaphragmatic hernia with colonic herniation with no evident barium extravasation into pleural cavity (Fig $2 \& 3)$. 


\section{Figure 2}

( Legend Fig 2 shows barium examination film with herniation of large bowel into left hemithorax., arrow. Normally located stomach and chest tube in situ are noted)

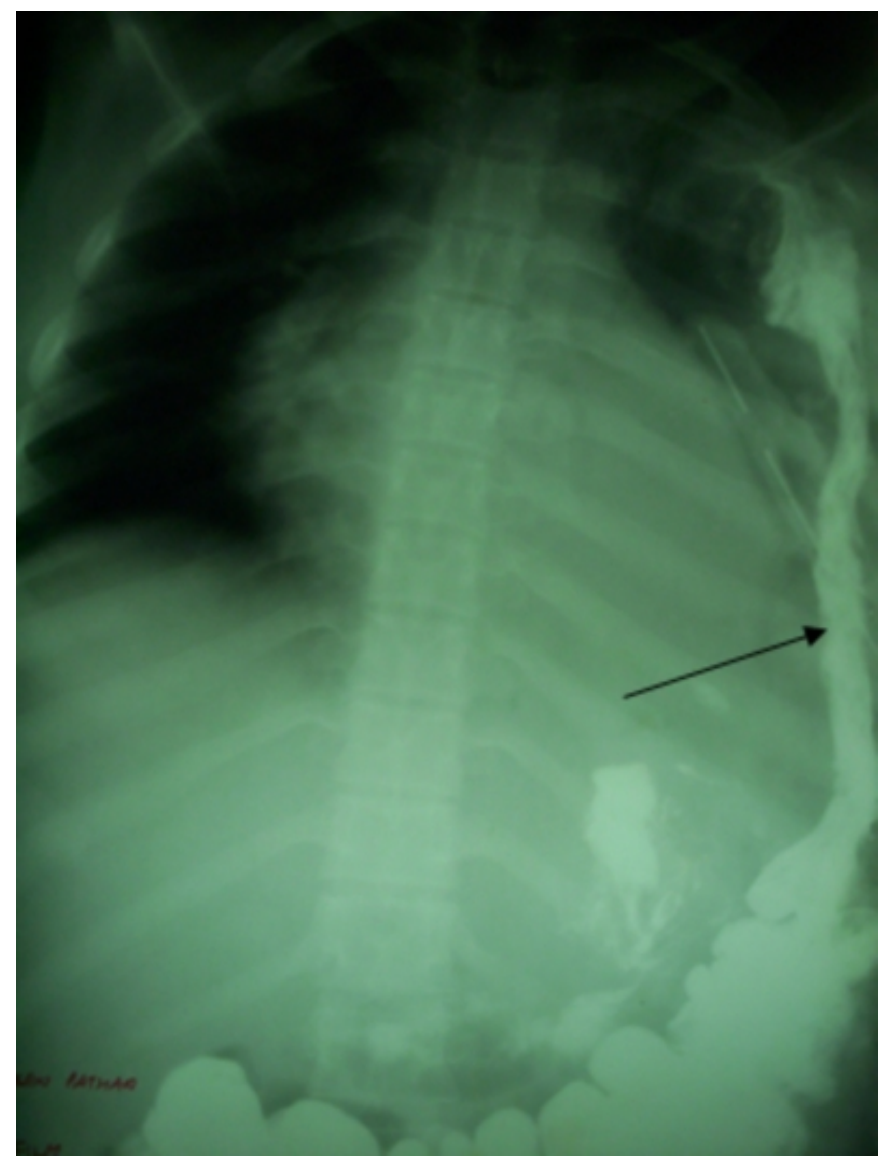

\section{Figure 3}

( Legend Fig 3 shows another barium examination film with evident herniation of splenic flexure of colon )

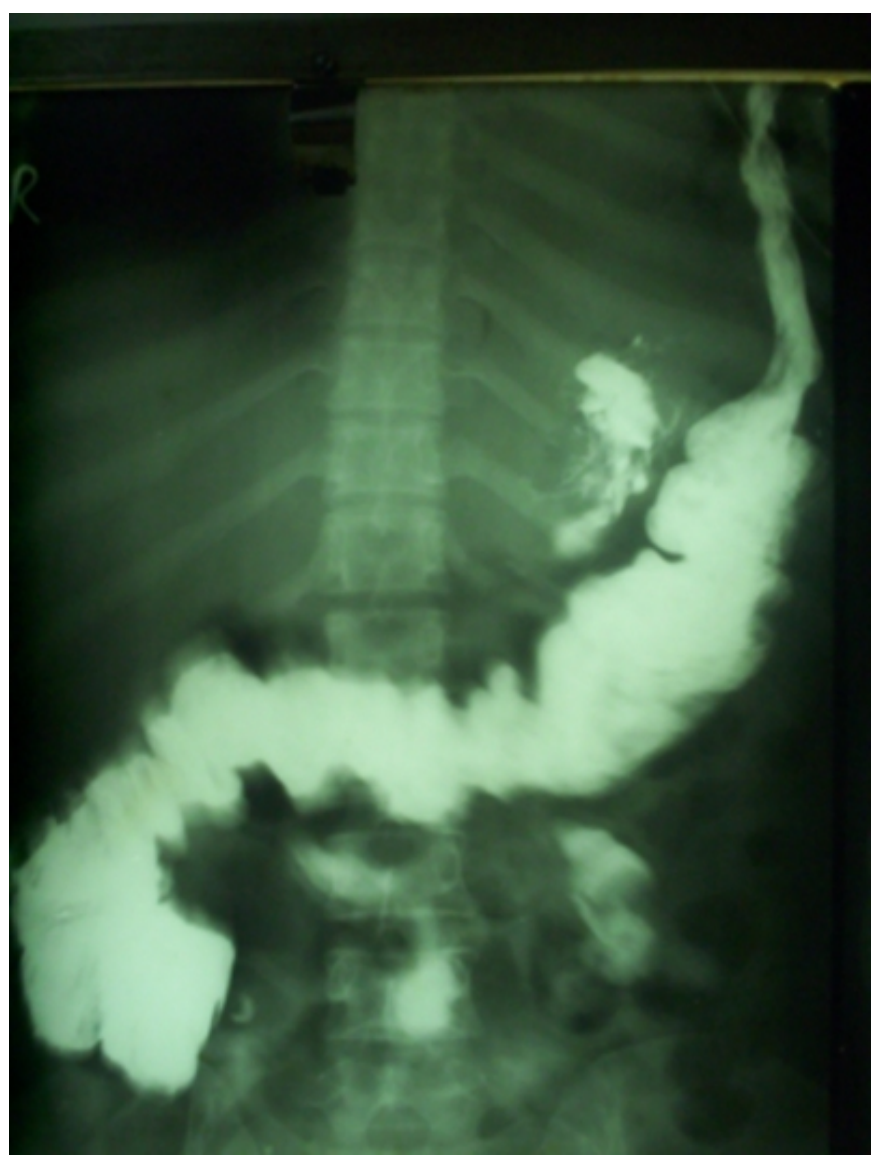

On further questioning the patient and her relatives admitted to history of blunt thoraco-abdominal trauma more than six months back for which she was given conservative treatment by the local practitioner with no further investigation or surgical treatment carried out.

Based on this diagnosis of traumatic left diaphragmatic hernia with possible colopleural fistula as a cause of left pleural effusion and chest tube ascariasis was suggested. Her stool examination was carried out which revealed ovas of ascaris Lumbricoides (round worm) with heavy parasitic load.

Patient was subsequently operated upon with intraoperative findings of traumatic defect in the left dome (Fig 4) and herniation of splenic flexure and part of descending colon (Fig 5 ) through it into the left pleural cavity. 


\section{Figure 4}

( Legend Fig 4 intraoperative photograph showing defect(arrow) in left diaphragmatic dome observed from abdominal aspect)

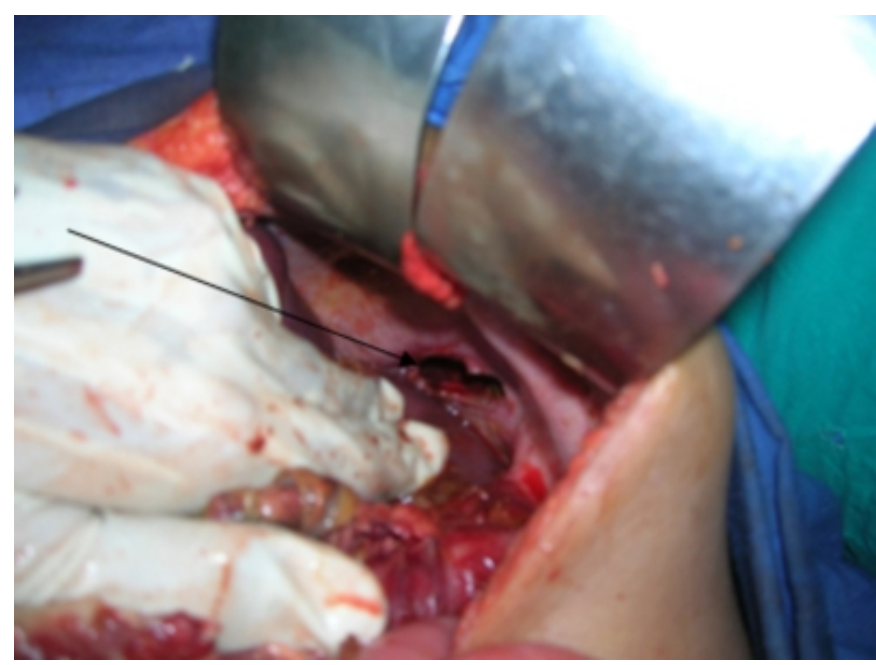

\section{Figure 5}

(Legend Fig 5 Introperative photograph showing herniation of splenic flexure and part of descending colon though the diaphragmatic defect into thoracic cavity)

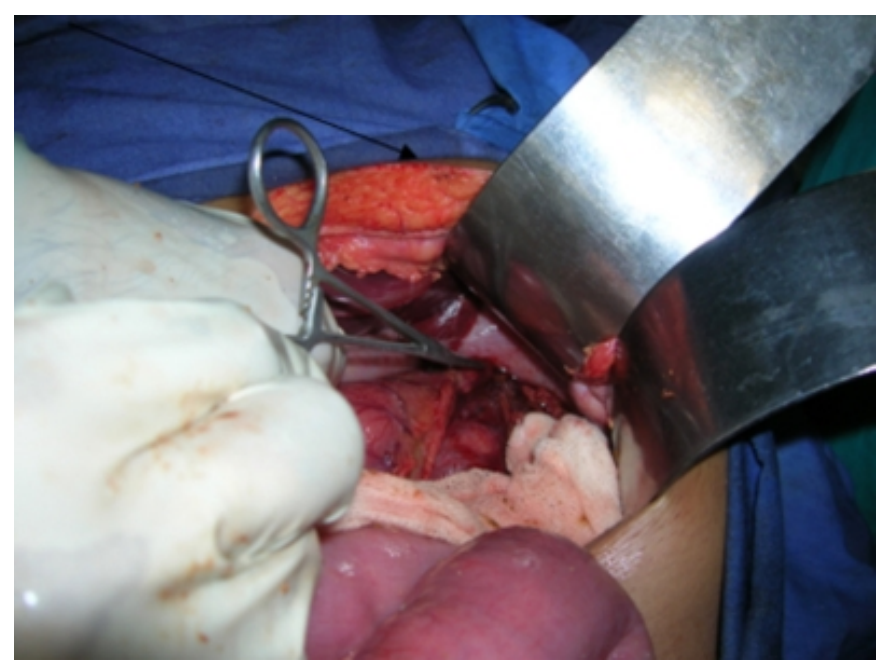

The herniated colonic segment revealed gangrenous portion (Fig 6 ) which was resected with end to end colonic anastomosis, reduction of the herniated colonic segment within the abdomen and repair of the diaphragmatic defect with loop ileostomy to allow colonic healing.

\section{Figure 6}

(Legend Fig 6 shows reduced gangrenous splenic flexure and descending portion of colon arrows )

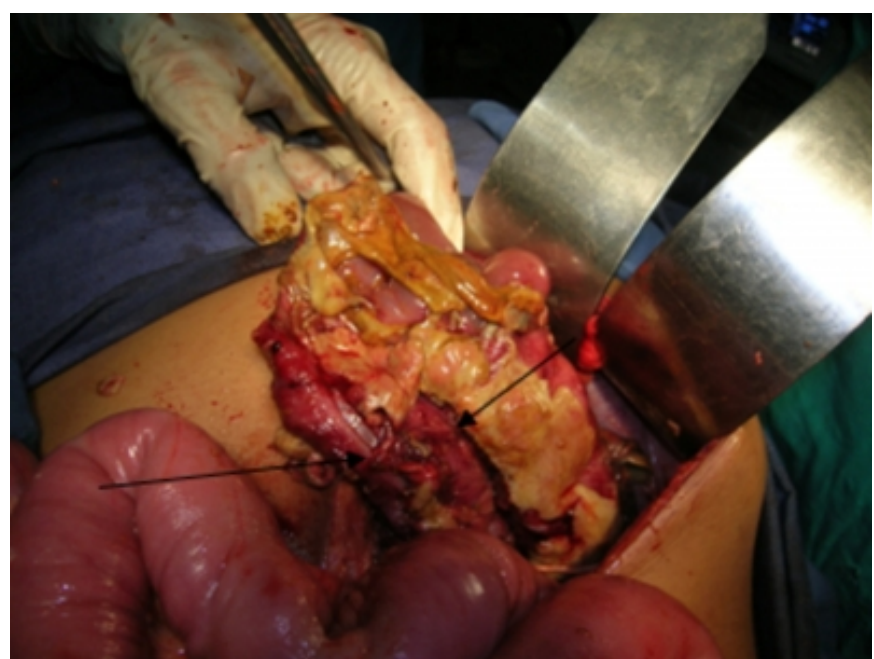

Presence of colopleural fistula was confirmed by the histopathology of the resected segment, which revealed a fistula tract. The patient showed uneventful post operative recovery and was administered Albendazole 400mg daily for three days during post operative convalescence for the worm infestation. She was discharged after four weeks with no complaints with subsequent closure of ileostomy after 3 months. Follow up visits revealed normal chest radiographic findings and bowel habits.

\section{DISCUSSION}

Our case is most unusual in the sense that pleural ascariasis was consequent to accidental migration of worms in left pleural space due to presence of colo-pleural fistula formed as a result of strangulation, gangrene and subsequent perforation of the herniated large bowel segment through the post traumatic left diaphragmatic defect.

Pleural ascariasis is very rare with very few cases reported in literature out of which only one case has reported the bizarre presentation of ascaris through the chest tube. None of the reported cases were associated with colopleural fistula or diaphragmatic herniation. Lone et $\mathrm{al}^{1}$ reported case of an Ascaris worm emerging through an intercostal chest tube inserted for right pleural effusion consequent to ruptured liver abscess into the right pleural cavity. Sen et $\mathrm{al}^{2}$ reported a case of tuberculous pyopneumothorax with bronchopleural fistula in whom a mature Ascaris worm migrated from the intestines to lodge in the pleural cavity. Zamora Almeida ${ }^{3}$ reported a patient who underwent thoracic surgery due to acute respiratory syndrome in whom an Ascaris worm was 
surprisingly found obstructing the probe after an exploratory left thoracotomy.

Post traumatic diaphragmatic hernia is a well-recognized complication of blunt and penetrating injuries to the abdomen and thorax with resultant stomach, large bowel or splenic herniation and is predominantly left sided. ${ }^{5}$ However strangulation/incarceration of the large bowel that migrates through traumatic diaphragmatic hernia into the thorax with its subsequent perforation and the development of colopleural fistula are rare. ${ }^{6,7}$ This clinical presentation of traumatic diaphragmatic hernia can be delayed in its appearance and may occur months or years after the initial injury $^{5-7}$ as in our case.

Review of literature reveals less than fifteen reported cases of colo-pleural fistula associated with traumatic diaphragmatic herniation of colon. However none of the cases presented with pleural ascariasis as in our case.

Most recently Khan and associates ${ }^{5}$ reported a case of faecopneumothorax in a young male consequent to necrotic incarcerated colon in setting of post traumatic diaphragmatic hernia with diagnosis made radiologically and confirmed on surgery as in our case.

J Kelly et $\mathrm{al}^{6}$ reported case of 22 year old male with delayed presentation of diaphragmatic rupture and herniation presenting as an acute tension having faecopneumothorax, strangulated \& gangrenous left sided diaphragmatic hernia containing a perforated loop of transverse colon on surgery.

Hiday et $\mathrm{al}^{7}$ reported case of $28 \mathrm{yrs}$ old woman having recent history of premature stillbirth presenting with signs of rightsided hydrothorax with feculent fluid on chest tube insertion. Radiological investigations suggested colothorax communication and surgery revealed a herniated colon into right side of the thorax with a fistula between the hepatic flexure of colon and right thorax, confirmed by the histopathology.

Vermillion et $\mathrm{al}^{8}$ have reported a case of tension faecopneumothorax resulting from traumatic left diaphragmatic herniation with left colonic necrosis.

Seelig et $\mathrm{al}^{9}$ reported a patient who, two years after being treated for a stab wound to the chest, presented with an acute tension faecopneumothorax caused by the incarceration of the large bowel in the thoracic cavity after an intrathoracic perforation.
Lacayo et $\mathrm{al}^{10}$ reported the case of a 20 -year-old woman who developed post cesarean section left pleural effusion and tension pneumothorax with drainage of liquid stool from chest tube. At surgery she was found to have a left diaphragmatic defect with herniation, strangulation, and perforation of the transverse colon into the pleural cavity. She had sustained a left lower hemithorax stab wound 2 years prior to admission.

Reddy et $\mathrm{al}^{11}$ reported a case of colopleural fistula, resulting from strangulation and perforation of a diaphragmatic hernia and presenting as tension pneumothorax. The hernia was most likely a consequence of a stab wound to the left side of the chest four years before admittance.

Radin and associates $^{12}$ have reported case of colopleural fistula, after undiagnosed diaphragmatic rupture leading to colon herniation and necrosis with rupture and empyema.

There is no universally accepted management for colopleural fistulas. Conservative treatment with total parenteral nutrition can be considered in selected uncomplicated cases, or where surgery is contraindicated due to associated comorbidity. Successful conservative management might be difficult, due to the pressure gradient between the abdominal and pleural end of such fistulas or when the fistulous tract is covered with mucosa.

Surgical management is essential when there is associated complex pleural pathology, with or without colonic pathology such as distal obstruction, ischemic bowel necrosis, malignancy, or a complex network of established true fistulas ${ }^{13}$, as was the situation in our case.

\section{SUMMARY}

Our case highlights an extremely rare and probably previously unreported combination of chest tube ascariasis with colopleural fistula in setting of post traumatic diaphragmatic hernia with delayed presentation, suspected clinico-radiologically and confirmed on surgery.

\section{References}

1. Lone RA, Wani ML, Manzoor M, Sharma ML, Lone GN, Shah $\mathrm{M}$ et al. Ascaris through a chest tube: a rare presentation Ulus Travma Acil Cerrahi Derg 2010 Mar; 16(2):183-4.

2. Zamora Almeida O. Localization of Ascaris lumbricoides in the thoracic cavity. Report of a case. Rev Cubana Med Trop 1976;28:71-5.

3. Hegarty MM, Bryer JV, Angorn IB, Baker LW. Delayed presentation of traumatic diaphragmatic hernia. Ann Surg. 1978 August; 188(2): 229-233.

4. Khan MA, Verma GR. Traumatic diaphragmatic hernia 
presenting as a tension fecopneumothorax. Hernia. 2010 Jan 7. [Epub ahead of print] PMID: 20054598

5. Kelly J, Condon E, Kirwan W, Redmond H. Posttraumatic tension faecopneumothorax in a young male: case report. World J Emerg Surg. 2008; 3: 20.

6. El Hiday AH, Khan FY, Almuzrakhshi AM, El Zeer H, Rasul FA. Colopleural fistula: Case report and review of the literature Ann Thorac Med. 2008 Jul-Sep; 3(3): 108-109. 7. Vermillion JM, Wilson EB, Smith RW. Traumatic diaphragmatic hernia presenting as a tension fecopneumothorax. Hernia. 2001 Sep;5(3):158-60. 8. Seelig MH, Klingler PJ, Schonleben K. Tension fecopneumothorax due to colonic perforation in a diaphragmatic hernia. Chest 1999;115:288-91.
9. Lacayo L, Taveras JM, Sosa N, Ratzan KR. Tension fecal pneumothorax in a postpartum patient. Chest 1993;103:950-1.

10. Reddy SA, Vemuru R, Padmanabhan K, Steinheber FU. Colopleural fistula presenting as tension pneumothorax in strangulated diaphragmatic hernia: Report of a case. Dis Colon Rectum 1989;32:165-7.

11. Radin D.R., Ray M.J., Halls J.M. Strangulated diaphragmatic hernia with pneumothorax due to colopleural fistula. AJR 1986;146:321-2.

12. Papagiannopoulos K, Gialvalis D, Dodo I, Darby MJ. Empyema resulting from a true colopleural fistula complicating a perforated sigmoid diverticulum. Ann Thorac Surg 2004;77:324-6. 


\section{Author Information}

Sameer R. Verma, MD,DNB

Subharti Medical College

Vandana Sardana, MBBS

Subharti Medical College 